\title{
Dynamic Performance Improvement of Pitch Angle Control Using PID and PIDA Controllers for Wind Generation Systems
}

\author{
Asmaa G.Ameen $^{1}$, I. Hamdan ${ }^{2}$, Shuaiby Mohamed ${ }^{3}$, GT Abdel-Jaber ${ }^{4}$

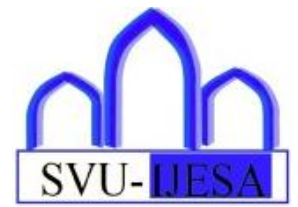

\begin{abstract}
Recently, wind energy is one of energy sources most have been devoted much awareness as result of shortage of energy. This study shows loads which are formed in the rotating shaft of wind turbine (WT). These loads cause disturbances on the blades, which leads to damage the blades. These loads can be exceeded, and the amount of productive energy can be controlled by using a good control unit that adjusts the angle of the WT blade. For the previous purpose, independent electric motor is used to control blade pitch, this process called pitch control (PC) system. This paper presents a mathematical model of PC system that is controlled by using two different controllers in MATLAB/Simulink; proportional -integral-derivative controller (PID) and proportional -integral-derivative-acceleration (PIDA). In this system three different functions are used as reference pitch angle; unit step function, sinewave function and step change signal which are used on control system without any controller and it is found that output system isn't reached to a reference value for three functions. The steady state error is equal to $76 \%$ when step function is used, so the controller is needed for a system. When PID and PIDA controllers are used, the time domain specification of output is improved. The steady state error in PID and PIDA controllers is $9 \%$ and $0.014 \%$ respectively. It is found that the better time domain specification is given by PIDA. PID and PIDA controllers are tested with sinewave and step change, PIDA is also produced the best response.
\end{abstract}

\footnotetext{
Received: 14 December 2020/ Accepted: 26 December 2020

$\square$ Corresponding authors:

${ }^{1}$ Asmaa G. Ameen,eng_mec_asm@yahoo.com

2I. Hamdan, IbrahimHamdan86@eng.svu.edu.eg

3 Shuaiby Mohamed,shuaiby.mohamed@aun.edu.eg

${ }^{4}$ GT Abdel-Gaber,gtag2000@yahoo.com

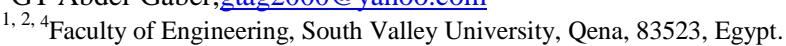

${ }^{3}$ Faculty of Engineering, Assiut University, Assiut, Egypt.
}

Keywords: Wind turbine; pitch control; PID controller; PIDA controller; wind mechanical model.

\section{Introduction}

One of the biggest problems that humanity faces today is energy squeezes. As a rising in the demand for electric energy along with the limited supply of fossil fuels, there has become a need to shift from human dependence on traditional resources to dependence on natural resources.

Wind energy is one of the three most important sources of energy, which is solar energy and geothermal energy, it is obtained by converting kinetic energy into mechanical energy, and then through a wind turbine generator, it is converted into electrical energy [1]. Since wind is a very important source of energy, it is important to devise a method to predict the behavior of the wind.

Figure.1 shows the construction of WT [2]. The WT's major components are blades, nacelle, tower and main controller [2]. The nacelle has a gear box, a generator, a transformer and a power converter. The gear box connects the shaft of the turbine blades and the shaft of the generator blades due to the wind rotating the blades [3]. Power generated from the generator is sent to the grid by a transformer [4]. Mostly on blade side and on the generator side, non -torque loads are added to the WT as input and output. These non-torque loads effects on the mechanical load and stress of the WT drive train [5]. In addition, the rotational load affects the mechanical load and causes stress on the WTs. Wind on the side of the input shaft also creates unexpected loads, such as abrupt shifts in wind speed direction, uneven blade loading, and wind disruption [5].

The stochastic nature of the wind defines the need for WT to run at various wind speeds that decide the turbine's operating regimes [6]. There are some features to be considered for each of these regimes. Controllers need to be designed and implemented to sustain efficiency of WT under these stipulations [7]. A. Ziouh, and et el [8] is studied advanced control due to the controls used must be 
robust enough to be able to operate properly due to a stochastic essence of the wind and when bursts of wind occur.
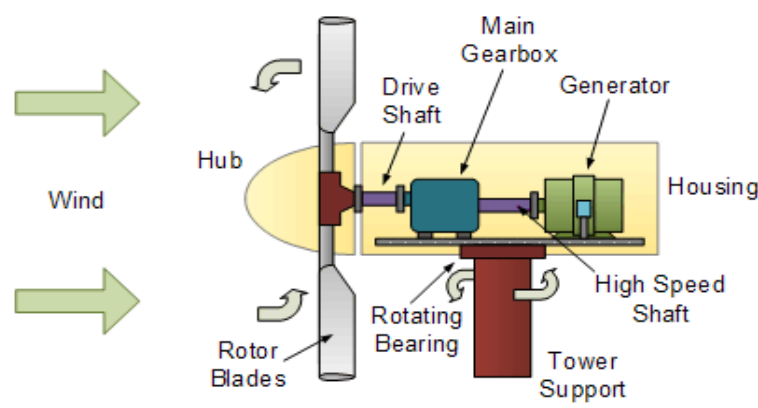

Fig. 1 Main parts of WT [2].

The lift profile of the rotor blades may have improved, in addition to the tools to control the pitch angle of inclination controllers, resulting in aerodynamics and other loads being minimized around the blades as R.D., and et el are presented [9]. Silpa Baburajan and et el are used PID controller with only step function to control on the mathematical model of PC system [10]. This paper is structured as follows: section 2 demonstrated WT system model with pitch actuator. Model of pitch motor is displayed on section 3. Section 4 shows the model of drive train. The PC system with PID and PIDA controller is set out in section 5. Section 6 presented a simulation and results of PC system. This study is concluded in section 7 .

\section{WT system model with pitch actuator}

WT system model is displayed by the block diagram that shown as Fig. 2 [11].

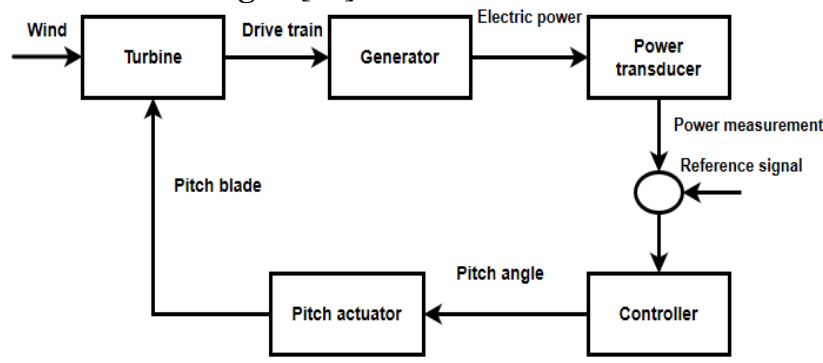

Fig. 2 WT model with feedback control system.

\section{Model of Pitch Motor}

The pitch motor is used to rotate blades around their linear axes; the actuator model depicts the dynamic perform between the requirement pitch of the PC and the measurement of the pitch angle[11].

The variation of the pitch angle is given by the following equations.

$$
\left.\begin{array}{l}
d \beta / d t=\left(\beta_{d}-\beta\right) / T_{\beta} \\
T_{\beta} . d \beta / d t+\beta=\beta_{d}
\end{array}\right\}
$$

Going to apply Laplace transformation

$$
\begin{aligned}
& \beta / \beta_{d}=1 /\left(s . T_{\beta}+1\right) \\
& \beta / \beta_{d}=1 /(0.5 s+1)
\end{aligned}
$$

Eq.3 represents the needed transfer function. It is possible to define the pitch motor time constant, $T_{\beta}$, From the initial WT's [11] parameters as shown in Table1.

Table 1 WT's initial parameters

\begin{tabular}{cc}
\hline Parameters & Value \\
\hline Power of generator, $P_{g}$ & $1000 \mathrm{KW}$ \\
Generator speed, $W_{g}$ & $1500 \mathrm{rpm}$ \\
Turning speed of rotor, $W_{t}$ & $20 \mathrm{rpm}$ \\
Radius of WT blade, $R$ & $35 \mathrm{~m}$ \\
Reference of pitch angle, $\beta_{d}$ & 0 to $90 \mathrm{deg}$ \\
Rate of pitch angle transition & $0.6 \mathrm{deg} / \mathrm{sec}$ \\
Regulation of pitch angle accuracy & $0.3 \mathrm{deg}$ \\
Damping coefficient, B & $2 \mathrm{~N} . \mathrm{m} / \mathrm{rad} / \mathrm{sec}$ \\
Inertia of Drive train , $J_{t}$ & $0.75 \mathrm{~N} . \mathrm{m} 2$ \\
\hline
\end{tabular}

\section{Model of drive train}

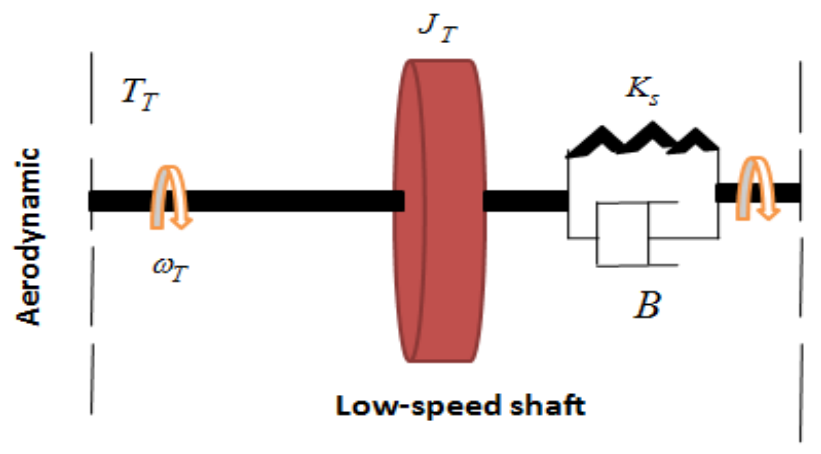

Fig.3 Drive train mechanical model.

The drive train mechanical model is presented as Fig.3. In the following differential equations, the drive train dynamics are constructed [11].

$$
\left.\begin{array}{l}
J_{T} . d / d t\left(w_{T}\right)=T_{T}-\left(K_{s} \delta \theta+B w \delta w\right) \\
d / d t(\delta \theta)=\delta w
\end{array}\right\}
$$

By using second low of motions

$$
J d w / d t=T-B w
$$




$$
\left.\begin{array}{l}
J . w s=T-B w \\
w / T=(1 / B) /((J / B) . s+1) \\
=0.5 /(0.375 s+1)
\end{array}\right\}
$$

where $w$ is the resultant value of WT and generator shaft speed, $J$ is the resultant value of WT and generator shaft inertia, $T$ is the resultant value of WT and generator shaft torque.

Table 2 presents the parameters of the modeling drive train.

\begin{tabular}{|c|c|c|c|}
\hline $\begin{array}{l}\text { Parame } \\
\text {-ter }\end{array}$ & Description & $\begin{array}{l}\text { Parame } \\
\text {-ter }\end{array}$ & Description \\
\hline$\overline{J_{T}}$ & WT inertia [kg.m2] & $w_{T}$ & $\begin{array}{c}\text { WT speed } \\
\text { shaft[rad/sec] }\end{array}$ \\
\hline$J_{G}$ & $\begin{array}{c}\text { Generator inertia } \\
\text { [kg.m2] }\end{array}$ & $w_{g}$ & $\begin{array}{l}\text { Generator shaft } \\
\text { speed[rad/sec] }\end{array}$ \\
\hline$K_{s}$ & $\begin{array}{c}\text { Stiffness coefficient } \\
{[\mathrm{N} . \mathrm{m} / \mathrm{rad}]}\end{array}$ & $\theta_{T}$ & $\begin{array}{c}\text { WT shaft } \\
\text { angle[rad/sec] }\end{array}$ \\
\hline$B$ & $\begin{array}{l}\text { Damper coefficient } \\
{[\mathrm{N} . \mathrm{m} / \mathrm{rad} / \mathrm{sec}]}\end{array}$ & $\theta_{g}$ & $\begin{array}{l}\text { Generator shaft } \\
\text { angle[rad] }\end{array}$ \\
\hline$T_{T}$ & WT torque[N.m] & $1: n_{\text {gear }}$ & Gear ratio \\
\hline$T_{G}$ & $\begin{array}{c}\text { Generator } \\
\text { electro-mechanical } \\
\text { torque [N.m] }\end{array}$ & & \\
\hline
\end{tabular}

Table 2 parameters of mechanical drive train model

\section{PC with PID and PIDA controllers}

PC system is in a WT's hub, where a pitch actuator is necessary for each blade. Technicians typically have to travel a remote area clamp 80 to $160 \mathrm{~m}$ to fix or service a pitch controller whether the turbine comes fitted with a lift or small elevator [12]. The pitch angle of blades is enhanced by using controller, which making it suitable for wind speed [13]. PID and PIDA controllers are used in this study.

\subsection{PID controller}

PID controller is composed of three different gains: proportional gain $\left(\mathrm{K}_{p}\right)$, integral gain $\left(K_{i}\right)$ and derivative gain $\left(K_{d}\right)$ as shown in Fig.4 [14].

$G(\mathrm{~s})=\mathrm{K}_{p}+K_{i} \frac{1}{s}+K_{d} s$

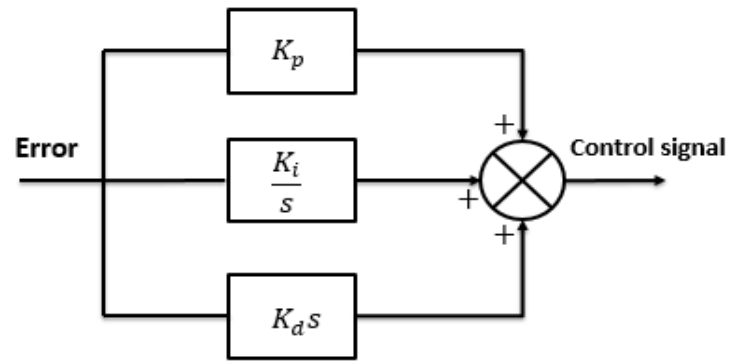

Fig.4 Block diagram of PID controller.

\subsection{PIDA controller}

PIDA is just like PID controller ,but it has an additional gain parameters which is the acceleration gain $\left(K_{a}\right)$ as it is the third order system and additional stabilizing filter elements. The block diagram of PIDA controller is presnted in Fig.5 [14].

$$
G(\mathrm{~s})=\frac{K_{a} s^{3}+K_{d} s^{2}+K_{p} s+K_{i}}{s^{3}+\alpha s^{2}+\beta s}
$$

where $\alpha$ and $\beta$ are new parameters which are used to add new roots to the characteristics equation to improve the response's stability limits.

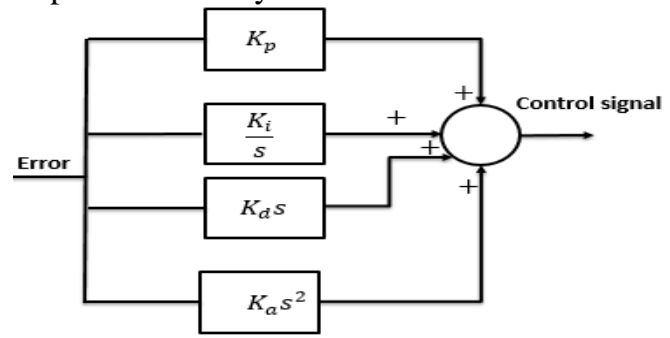

Fig.5 Block diagram of PIDA controller.

PID and PIDA controllers are used with gains as shown in Table3 which are calculated by using trial and error method.

Table 3 Gains value of PID and PIDA controller for unit step and step change function

\begin{tabular}{ccccccc}
\hline $\begin{array}{c}\text { Controller } \\
\text { parameters }\end{array}$ & $K_{p}$ & $K_{i}$ & $K_{d}$ & $K_{a}$ & $\alpha$ & $\beta$ \\
\hline PID controller & 0.27 & 1.017 & 0 & - & - & - \\
& & & & & & \\
PIDA controller & 120 & 100 & 50 & 10 & 50 & 100 \\
\hline
\end{tabular}

\section{Simulation and Result of the PC system}

The mathematical model is formulated to a simulation model without controller, with PID controller and PIDA controller [15] by using MATLAB/Simulink as shown in 
Fig.6, Fig.7 and Fig.8 respectively. PC system is used three different functions as reference pitch angle of it, they are unit step function, sinewave function and step change input signal.

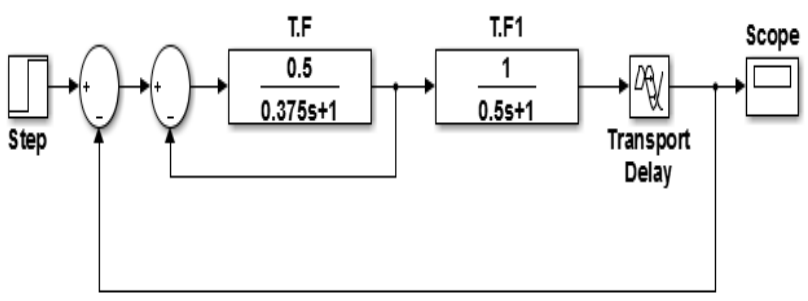

Fig.6 Simulink model of PC system without controller.

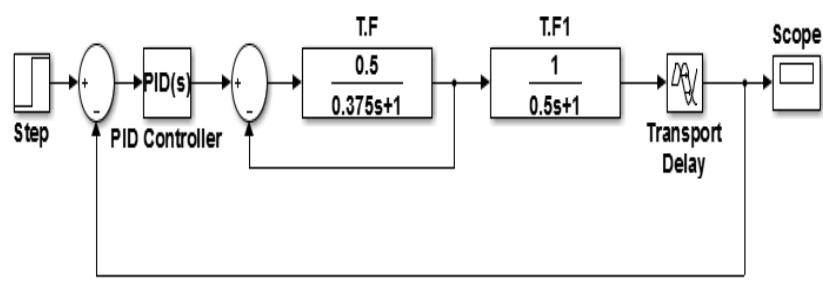

Fig.7 Simulink model of PC system with PID controller.

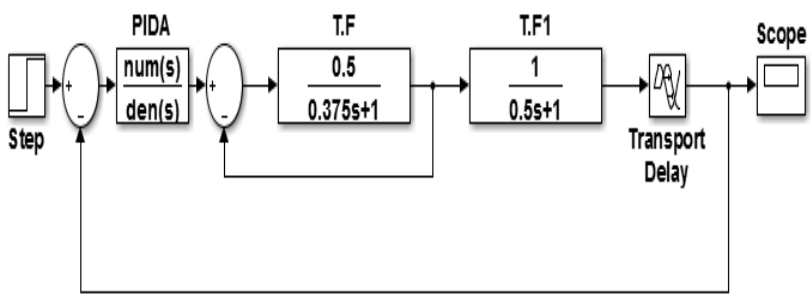

Fig.8 Simulink model of PC system with PIDA controller.

6.1 Simulation result of PC system with unit step function.

Pc system is used unit step input as a reference value of pitch angle. The simulation results of the output are shown in Fig.9 without and with controllers.

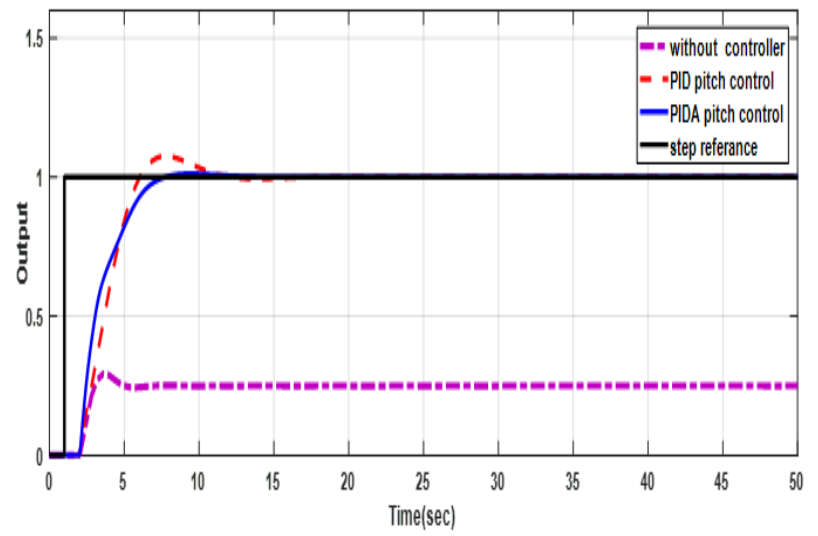

Fig.9 Step response of PC system without, PID, and PIDA controllers.
Table 4 refers to a comparison of pitch control system between controllers.

Table 4 Time domain specification comparison of PC system

\begin{tabular}{cccc}
\hline $\begin{array}{c}\text { Time domain } \\
\text { Specification }\end{array}$ & $\begin{array}{c}\text { without } \\
\text { Controller }\end{array}$ & $\begin{array}{c}\text { PID } \\
\text { controller }\end{array}$ & $\begin{array}{c}\text { PIDA } \\
\text { controller }\end{array}$ \\
\hline Settling time & 6.6502 & 16.75 & 9.227 \\
Peak overshot & 0.05 & 0.0752 & 0.0121 \\
Steady state error & $76 \%$ & $9 \%$ & 0.014 \\
\hline
\end{tabular}

It is noted that the system output is not reached to a reference value with high steady state error and settling time. When PID controller is used, steady state error dropped to $9 \%$ but PIDA presented the better steady state error and settling time.

6.2 Simulation result of PC system with sinewave function.

PC system is used sinewave function as a reference value of pitch angle. The simulation results of the output are shown in Fig.10. In this case we used different input to test the controllers. From Fig.10 it is noted that PIDA produced the best response of the system.

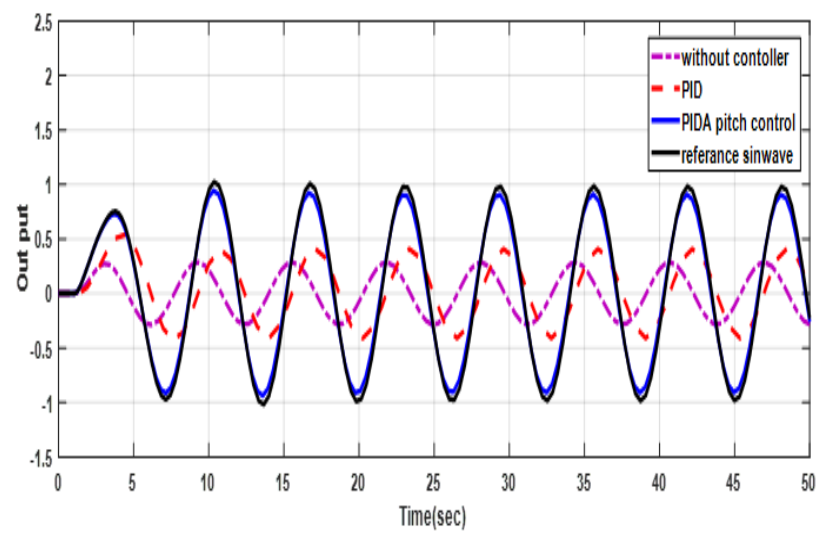

Fig.10 Sine-wave response of PC system without, PID and PIDA controllers.

6.3 Simulation results of PC system with Step change reference input.

In this case step change signal as shown in Fig.11 is used as a reference value of pitch angle. 


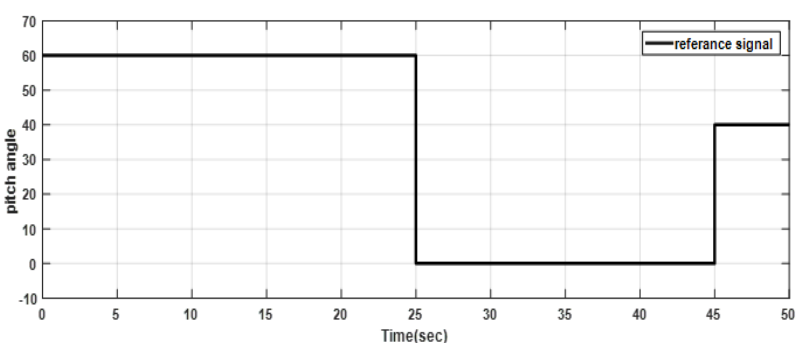

Fig.11 step change signal.

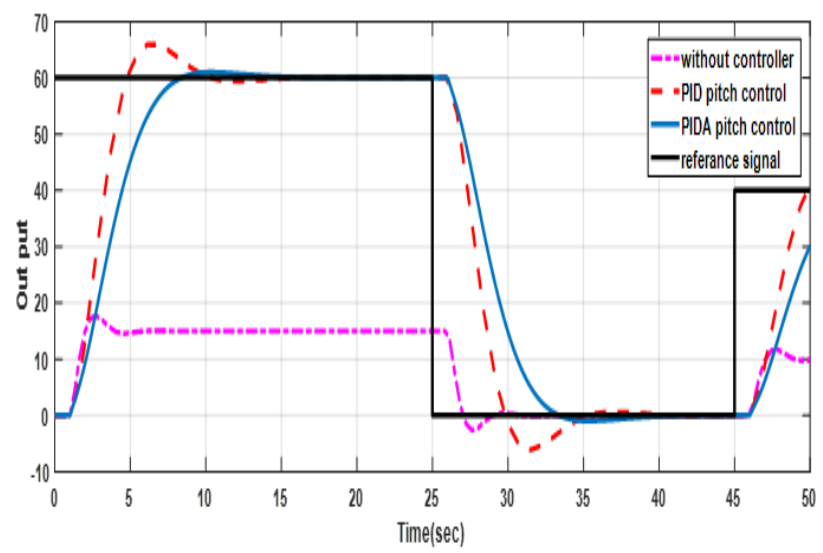

Fig.12 Step change response of PC system without, PID, and PIDA controllers.

From Fig.12 it is noted that the best response of the system is produced by PIDA controller.

\section{Conclusion}

In this study, the mathematical model of PC system is formulated in to simulation model by using MATLAB/Simulink and improved with PID and PIDA controller. PC system is used three different functions as a reference pitch angle of it. Firstly; unit step function is used on control system without any controller and it is found that output system isn't reached to reference value because the steady state error equal to $76 \%$, this means that the system needs to controller. When PID and PIDA controllers are used, the time domain specification of output is improved. The steady state error in PID and PIDA controllers is equaled to $9 \%$ and $0.014 \%$ respectively, settling time in PID and PIDA is equaled to 16.75 second and 9.22 second respectively, and the peak overshoot of PID and PIDA is equaled to 0.0752 and 0.0121 respectively. Secondly; sinewave is used as input value.in this case PIDA is produced the best result. Thirdly; step change input signal is used and also PIDA controller gives the better output. From the previous results we concluded that the performance of PIDA controller is the best. In the future work we will be conducting nonlinear robust controller design and improving overall performance of WT system.

\section{References}

[1] Civelek, Zafer, Ertuğrul Çam, Murat Lüy, and Hayati Mamur. "Proportional-integral-derivative Parameter Optimisation of Blade Pitch Controller in Wind Turbines by a New Intelligent Genetic Algorithm." IET Renewable Power Generation 10.8: 1220-228. (2016).

[2] Crespo, J. Hernandez, S. Frandsen, " Wind Energy 2", 1-24 (1998).

[3] J.G. Leishman,: "Wind Energy 5", 86-132 (2002).

[4] L.J. Vermeer, J.N. Sørensen , A. Crespo," Progress in Aerospace Sciences 39", 467-510 (2003).

[5] Jacopo Antonelli, "Reduced order modelling of wind turbines in matlab for grid integration and control studies"1-2 (2012).

[6] S. Iniyan, G. J. Herbert, E. Sreevalsan, and S. Rajapandian, "A review of wind energy technologies," Renewable and sustainable energy Reviews, vol. 11, pp. 1117-1145, (2007).

[7] G. ZITO, I.D. LANDAU, "Digital Control Systems".Springer-Verlag, London, (2002).

[8] Ziouh,S. Rhaili, A. Abbou, , and R. Elidrissi, "Comparative study between PI and FUZZY logic controller in vector controlled fivephase PMSG based variable-speed wind turbine", in Compatibility, Power Electronics and Power Engineering (CPE-POWERENG), 2018 IEEE 12th International Conference on, , pp. 1-6 (2018).

[9] R.D., and Sharma "Feedforward Learning Control for Individual Blade Pitch Control of Modern Two-Bladed Wind Turbines"(2013).

[10] S. Baburajan , "Pitch control of wind turbine through PID,fuzzy and adaptive fuzzy -PID controller"(Order No.10638758).Available from pro Quest Dissertation \&Theses Global(1975472670)(2017).

[11] E. Muljadi and C. P. Butterfield, "Pitch-controlled variable-speed wind turbine generation," IEEE transactions on Industry Applications, vol. 37, pp. 240-246, (2001).

[12] PETROVIC and M. JELAVIC, "Design of a Wind turbine pitch controller for loads and fatigue reduction", Electrical Engineering Institute, Proceedings of the European Wind Energy Conference \& Exhibition - EWEC, Milan, Italy, (2007).

[13] R H. Bishop and Dorf, R. C. "Modern Control Systems", 7th edition, Addison Wesley,(1995).

[14] S. Juug, Dorf, R. C., J. Dawes and L. Ng "An s-Plane Analytic Technique for Lead-Lag Controller Design", Proc. of American Control Conference, pp. 2227- 2228, Seattle, (1995).

[15] C. Tan and H. Wang, "A Review on Pitch Angle Control Strategy of Variable Pitch Wind Turbines", Advanced Materials Research, vol. 772, pp. 744-748, (2013). 